\title{
Seasonal variation in microhabitat of salamanders: environmental variation or shift of habitat selection?
}

Enrico Lunghi, Raoul Manenti, Gentile Francesco Ficetola

Relationships between species and their habitats are not always constant. Different processes may determine changes in species-habitat association: individuals may prefer different habitat typologies in different periods, or they may be forced to occupy a different habitat in order to follow the changing environment. The aim of our study was to assess whether cave salamanders change their habitat association pattern through the year, and to test whether such changes are determined by environmental changes or by changes in preferences. We monitored multiple caves in Central Italy through one year, we monthly measured biotic and abiotic features of microhabitat and recorded Italian cave salamanders distribution. We used mixed models and niche similarity tests to assess whether species-habitat relationships remain constant through the year. Microhabitat showed strong seasonal variation, with the highest variability in the superficial sectors. Salamanders were associated to relatively cold and humid sectors in summer, but not during winter. Such apparent shift in habitat preferences mostly occurred because the environmental gradient changed through the year, while individuals generally selected similar conditions. Nevertheless, juveniles were more tolerant to dry sectors during late winter, when food demand was highest. This suggests that tolerance for suboptimal abiotic conditions may change through time, depending on the required resources. Differences in habitat use are jointly determined by environmental variation through time, and by changes in the preferred habitat. The trade-offs between tolerance and resources requirement are major determinant of such variation. 


\section{Seasonal variation in microhabitat of salamanders: environmental variation}

2 or shift of habitat selection?

3

4

5 Enrico Lunghi ${ }^{1,2,3, *}$, Raoul Manenti ${ }^{4}$, Gentile Francesco Ficetola ${ }^{5,6,7}$

6

$7 \quad{ }^{1}$ Universität Trier Fachbereich VI Raum- und Umweltwissenschaften Biogeographie, Campus I,

8 Gebäude N Universitätsring 15, 54286 Trier, Germany

$9 \quad 2$ Natural Oasis, Via di Galceti 141, 59100 Prato, Italy

$10{ }^{3}$ Museo di Storia Naturale dell'Università di Firenze, Sezione di Zoologia "La Specola", Via

11 Romana 17, 50125 Firenze, Italy

$12{ }^{4}$ Dipartimento di Bioscienze, Università degli Studi di Milano. Via Celoria 26, 20133 Milano 13 Italy

$14 \quad{ }^{5}$ Dipartimento di Scienze dell'Ambiente e del Territorio e di Scienze della Terra, Università

15 degli Studi di Milano-Bicocca. Piazza della Scienza 1, 20126 Milano Italy

$16{ }^{6}$ Laboratoire d'Ecologie Alpine (LECA), Université Grenoble-Alpes, F-38000 Grenoble, France

$17{ }^{7}$ CNRS, LECA, F-38000 Grenoble, France

18

$19{ }^{*}$ Corresponding author. Tel.: +393391604627

20 E-mail addresses: enrico.arti@gmail.com 


\section{Abstract}

22 Relationships between species and their habitats are not always constant. Different processes

23 may determine changes in species-habitat association: individuals may prefer different habitat

24 typologies in different periods (i.e. seasons, life stages), or they may be forced to occupy a

25 different habitat in order to follow the changing environment. The aim of our study was to assess

26 whether cave salamanders change their habitat association pattern through the year, and to test

27 whether such changes are determined by environmental changes or by changes in preferences.

28 Through one year, we monthly monitored multiple caves in central Italy to measure biotic and

29 abiotic features of microhabitat, and recorded Italian cave salamander distribution. We used

30 mixed models and niche similarity tests to assess whether species-habitat relationships remain

31 constant through the year. Microhabitat showed strong seasonal variation, with the highest

32 variability in sectors nearby cave entrance. Salamanders were associated to relatively cold and

33 humid sectors in summer, but not during winter. Such apparent shift in habitat preferences

34 mostly occurred because the environmental gradient changed through the year, while individuals

35 generally selected similar conditions. Nevertheless, juveniles were associated with particularly

36 dry conditions during late winter, when food demand was highest. This suggests that tolerance

37 for suboptimal abiotic conditions may change through time, depending on the required resources.

38 Variation of environmental features and change in preferences can jointly determine variation of

39 habitat association patterns, and tradeoffs between tolerance and resource demand may play an

40 important role in such variation. 


\section{Introduction}

43 The use of habitat models to evaluate factors determining species distributions is becoming

44 increasingly prevalent in ecological research (Peterson et al. 2011; Warren 2012; Stein, Gerstner

$45 \&$ Kreft 2014). Such models help understanding the factors determining species occurrence, and

46 may allow predicting potential areas of occupancy, with important consequences for planning

47 adequate conservation actions (Domíguez-Vega et al. 2012; Bogaerts et al. 2013). Despite

48 repeated calls for mechanistic modelling (Kearney \& Porter 2009), correlative habitat models

49 remain the most frequently used approach. Correlative models combine data on species

occurrence (e.g. presence/absence, presence-only, abundance) with information on

environmental features, identifying statistical relationships which represent the basis for model

52 predictions (Guisan \& Thuiller 2005). Such models are based on the assumptions that species

53 presence is associated with favorable environmental features (species-habitat association)

54 (Godsoe 2010).

However, patterns of species-habitat association may be not consistent during time.

Analyses of habitat associations generally assume that species are at quasi-equilibrium with the environment, but this assumption may not always hold (e.g. during dispersion or contraction phases) (Saupe et al. 2014). Furthermore, differences in habitat association patterns may occur through two distinct, non-exclusive processes: the species may select different habitats across their life-time (selection change hypothesis), and environmental features may change through

61 time (environmental change hypothesis). According to the selection change hypothesis, a given 62 species may be associated with different environmental features in different time periods and/or

63 life stages. For instance, many species show seasonal activities, and select different

64 environments depending on the activities performed (e.g. nesting, foraging, wintering) 
65 (Seebacher \& Alford 1999; Brambilla \& Saporetti 2014). In the long term, temporal variation for

66 habitat association in a given species may also occur due to evolution of novel adaptations

67 (Nogués-Bravo 2009; Stigall 2012). According to the environmental change hypothesis,

68 temporal variation that exists for the many biotic and abiotic features can affect species

69 distribution (Kearney et al. 2013). Such variation may occur over both short (e.g., variation of

70 vegetation cover or temperature among the seasons) and longer timescales (e.g. climate change,

71 habitat degradation) (Saupe et al. 2014). Both selection changes and environmental changes may

72 influence the possibility of predicting species distribution in different time periods. Evaluating

73 whether habitat association pattern changes through time, and the factors determining such

74 variation, is extremely important to assess the transferability and generality of conclusions drawn

75 from habitat modeling.

76 Among amphibians, plethodontid salamanders represent a very interesting study case.

77 Due to their particular physiology, they need a narrow combination of environmental

78 characteristics, and actively search places with suitable microclimatic conditions (cold

79 temperature and high moisture; (Spotila 1972; Camp \& Jensen 2007). Cave salamanders (genus

80 Hydromantes) may live both in surface and subterranean environments, but must move

81 underground during the arid and hot Mediterranean summer, when the surface conditions

82 become hot and dry (Lanza et al. 2006; Ficetola, Pennati \& Manenti 2012). In subterranean

83 environments microclimatic features are often considered to remain approximately stable,giving

84 organisms the opportunity to inhabit caves constantly. Some studies have shown that cave

85 salamanders are associated with caves having specific environmental features, such as low

86 temperature, high humidity and presence of prey (Ficetola, Pennati \& Manenti 2012; Lunghi,

87 Manenti \& Ficetola 2014), but these studies have been often performed during summer, when 
outdoor conditions are particularly unsuitable for salamanders, and abundance in cave is highest. However, caves are not closed systems, and environmental characteristics within caves can change over time due to external influences (Romero 2009). Such fluctuations mostly affect areas near the entrance of caves (twilight zone) and can strongly influence cave communities (Ficetola, Pennati \& Manenti 2013; Camp et al. 2014; Lunghi, Manenti \& Ficetola 2014). Nevertheless, the few studies analyzing the seasonal variation in the distribution of European cave salamanders (Salvidio et al. 1994; Vignoli, Caldera \& Bologna 2008) did not test whether habitat selection changes through time.

The peculiar features of both caves and plethodontid salamanders make them an excellent system for species-habitat association studies. Cave environments are dominated by few, simple environmental gradients, such as light, depth, temperature, humidity and food availability (Romero 2009), affording simplistic habitat characterization. Furthermore, species are easily detectable inside the delimited cave environments (Ficetola, Pennati \& Manenti 2012), allowing a reliable identification of occupied and unoccupied sectors.

The aim of this study was analyzing the variation through time of species-habitat association in the Italian cave salamander (Hydromantes italicus). First, we used habitat models to identify the relationships between the distribution of salamanders and microhabitat features, evaluating if the pattern of microhabitat association is constant through time. Second, we assessed whether the temporal variation in microhabitat occurs because the species selects different environmental features through the year, or because habitat features are affected by seasonal variation (i.e. we evaluated the support of the environmental changes vs. selection change hypotheses). 


\section{Material and Methods}

112

\section{Authorizations}

114

115 All applicable institutional and/or national guidelines for the care and use of animals were

116 followed. The study was conducted under authorization of Apuan Alps Regional Park ( ${ }^{\circ} 5$,

117 4/04/2013), District of Prato ( ${ }^{\circ}$ 448, 2013), District of Pistoia ( $\mathrm{n}^{\circ}$ 0022597/2013/P) and District

118 of Lucca $\left(n^{\circ} 731,21 / 02 / 2013\right)$.

119

120

Surveys

121

122 For 12 months (from January 2013 to December 2013) we monitored 15 caves occupied by 123 Hydromantes italicus in the North of Tuscan Apennines (Central Italy, between 4352'42" N,

$1241^{\circ} 07^{\prime} 18^{\prime \prime} \mathrm{E}$ and $\left.43^{\circ} 59^{\prime} 51^{\prime \prime} \mathrm{N}, 10^{\circ} 13^{\prime} 48^{\prime \prime} \mathrm{E}\right)$. Preliminary surveys performed in 2012 indicated

125 the presence of $H$. italicus at all sites. Surveys were conducted during day-time. The order of

126 cave survey was chosen randomly, and the time interval between successive visits was 9-45

127 days. During surveys, for each cave we recorded monthly environmental data both inside and

128 outside caves. Outside caves, we registered air temperature (accuracy: $0.1^{\circ} \mathrm{C}$ ) and humidity

129 (accuracy: 0.1\%) using a thermo-hygrometer Lafayette TDP92, in a shaded area 5-10 $\mathrm{m}$ from the

130 entrance. The interior of each cave was divided into sectors of 3-m length, starting from the

131 entrance and extending to the deepest explored area: our exploration was conducted until the end

132 of the caves, or until the deepest sector reachable without speleological equipment. Three-m

133 sectors approximately correspond to the home range of Hydromantes during their hypogean 
134 activity (Salvidio et al. 1994). Overall, we recorded data from 121 cave sectors [average

135 development explored per cave: $24.2 \mathrm{~m}$ (range 6-60), corresponding to 2-20 sectors per cave]. At

136 the time of surveys, in each sector we recorded four parameters known to influence cave

137 salamanders. Air temperature, humidity and incident light (illuminance, measured using a

138 Velleman DVM1300 light meter, minimum recordable light: 0.1 lux) represent the abiotic

139 conditions of caves, which influence metabolism, water balance and activity (Kearney et al.

140 2013). The abundance of Meta menardi spiders was considered as a biotic variable. On the one

141 hand, Meta spiders are major predators of juvenile salamanders (Lanza et al. 2006). Furthermore,

142 Meta spiders are associated with areas showing high invertebrate abundance, and have been

143 proposed as an indicator of prey abundance in cave environments (Manenti et al., submitted).

144 See Ficetola et al. (2013) for additional details on the recording of cave features.

145 We used visual encounter surveys to assess the presence/absence of $H$. italicus and $M$.

146 menardi spiders in each sector. This standardized technique allows to verify the presence of

147 species in an area during a defined time (Crump \& Scott 1994; Jung et al. 2000). If possible,

148 salamanders were measured. Salamanders showing total length $>6.5 \mathrm{~cm}$ or with male secondary

149 characters were considered adults (Lanza et al. 2006), the remaining salamanders were

150 considered juveniles. All individuals were immediately released at the collection point.

\section{Statistical analyses}

Variation of environmental features of caves

155

We used linear mixed models (LMM) to analyze the temporal variation of cave 
157 microhabitat. We used the Akaike's Information Criterion corrected for small sample size

158 (AICc) to identify the combination of parameters that better explain the variation of

159 microclimatic features inside caves (Stephens et al. 2007). In LMM, we considered cave features

160 (temperature, humidity, illuminance) as dependent factors, while outdoor features (temperature

161 and humidity), linear distance from the cave entrance (hereafter, depth) and month of survey

162 were considered as independent factors. We also considered the interaction between depth and

163 month of survey. We also included the time of survey (hour and minute in which we began the

164 survey) as an additional independent variable. Cave and sector identity were considered as

165 random categorical variables, as they shows a typical combination of variables (both biotic and

166 abiotic) independently from their position and location. For all models, Variance Inflation Factor

167 was $<5$, confirming lack of collinearity issues (Fox 2002). Seasonal variation also occurs for the

168 distribution of cave spiders but was not analyzed here as it will be the focus of a separate study.

Relationships between species and environmental features

Not detecting a species during a survey does not necessarily mean that species is absent, as most species have detection probability $<1$ (MacKenzie et al. 2006). Standard approaches to

174 the analysis of detection probability assume that sites are closed to changes in the state of 175 occupancy for the duration of sampling (MacKenzie et al. 2006). However, cave salamanders

176 quickly modify their occupancy patterns throughout the year in response to environmental

177 variation (Briggler \& Prather 2006; Camp \& Jensen 2007; Vignoli, Caldera \& Bologna 2008),

178 and therefore violate the closed population assumption. Approaches assuming open populations

179 also exist but, in this study case, their implementation would require assumptions on population 
180 dynamics for which no data were available (Dail \& Madsen 2011). Sampling effort was

181 standardized across sectors. Therefore, following recommendations by Banks-Leite et al. (2014),

182 we preferred performing analyses using standard mixed models, while verifying that low

183 detection probability did not bias our results.

184 First, we used generalized linear mixed models (GLMM) assuming binomial error to

185 identify the relationships between the presence of salamanders and environmental features (air

186 temperature, humidity, illuminance and spider abundance) of each sector, throughout the 12

187 months of sampling. To assess whether the habitat selection pattern is constant through time, we

188 included the interactions between sampling month and environmental features. Sector and cave

189 identity were included as random categorical factors. We built all possible model combinations,

190 and ranked them using AICc. Complex models with AICc values higher than the simpler, nested

191 models were not considered as candidate models (Richards, Whittingham \& Stephens 2011). We

192 used a likelihood ratio test to assess the significance of terms in the best-AICc model. As

193 microhabitat selection may be different among age classes (Ficetola, Pennati \& Manenti 2013),

194 this analysis was repeated three times: first, considering all individuals, then considering adults

195 and juveniles separately.

196 The results of the previous models may be affected by imperfect detection. We used the

197 MacKenzie and Kendall (2002) approach to test detection probability of cave salamanders, on

198 the basis of data collected in 22 sectors from three different caves. These caves were surveyed in

199 late June-early July: during this interval, Hydromantes movements among sectors are expected to

200 be limited (Lanza et al. 2006). For these sectors, two surveys were performed 9 - 14 days apart,

201 therefore we assumed constant occupancy in this interval and estimated detection probability

202 using single-season closed population occupancy models with the unmarked package in R (Fiske 
$203 \&$ Chandler 2011). The analysis of detection probability was repeated twice: assuming constant 204 detection across sectors, and assuming that detection probability is related to distance from cave 205 entrance. We then used AIC to identify the best detection probability model.

206 Analyses (see results) showed a per-visit detection probability of 0.75 , i.e. two surveys

207 allow to ascertain presence/absences with 94\% confidence (Sewell, Beebee \& Griffiths 2010).

208 To assess the robustness of habitat models to imperfect detection, we also repeated the GLMM

209 analysis by comparing two contrasting periodsseasons: January-February and June-July.

210 Movements between superficial and deep sectors are more frequent during spring and autumn

211 (Lanza et al. 2006), thus we assumed that occupancy was relatively stable within these periods.

212 We merged data from two-months periods respectively into winter (January and February) and

213 summer (June and July), and repeated the analyses using the same variables of the best-AICc

214 models obtained from the analyses of full dataset.

215

216 Testing the stability of habitat selection pattern

217

218 We used niche equivalency tests to assess whether salamanders select sectors with similar

219 environmental features in different months, after taking into account differences for the

220 availability of microhabitat conditions (Broennimann et al. 2012). The similarity of the habitat

221 selection pattern in two distinct seasons was assessed using Schoener's $D$, a metric of niche

222 similarity (Warren, Glor \& Turelli 2008; Saupe et al. 2014). For equivalency tests, salamander

223 occurrences from different months were pooled and then randomly split in two datasets,

224 maintaining the same number of occurrences of the original datasets; Schoener's $D$ was then

225 calculated. This procedure was repeated 300 times, to assess whether niche similarity was 
226 significantly lower than expected by chance. The equivalency test was repeated for the two

227 environmental variables (temperature and humidity) for which habitat models suggested

228 differences among months. We focused on univariate rather than multivariate tests, because we

229 were interested on variation of habitat selection due to change of specific variables (Saupe et al.

230 2014). This analysis was performed on four months (January, February, June and July) showing

231 contrasting patterns of habitat association (see results), and during which we do not expect major

232 movements among cave sectors (i.e. within these intervals the quasi-equilibrium assumption is

233 more likely to be hold than when seasonal migrations occur). The analysis was performed on all

234 individuals together and for each age category (juveniles only and adults only). Since six

235 pairwise tests were performed for each group and for each variable, significance values were

236 corrected using sequential Bonferroni’s correction (Rice 1989).

237

238 Results

239

240

Variation of environmental features inside caves

Internal temperature was strongly related to external temperature and humidity, month,

243 depth and interaction between month and depth: all variables except depth were significant

244 (Tables 1a, 2a). Seasonal change led to thermal inversion inside caves: from late autumn to early

245 spring temperature increased with depth, while from late spring to early autumn temperature

246 decreased in the deep sectors (Fig. 1a). Humidity inside caves was strongly related to external

247 humidity, month, depth and to the time of survey. Furthermore, the significant interaction

248 between month and depth indicated that the humidity gradient was not constant through the year 
249 (Tables 1b, 2b). The deepest sectors showed high stability of humidity through time, while

250 fluctuations due to external variation were evident in sectors nearby the cave entrance. External

251 humidity was particularly high in autumn and spring, determining an increase of humidity in the

252 first sector of caves (Fig. 1b). Internal light incidence was related to depth and external humidity

253 (Tables 1c, 2c). The deepest sectors always showed lower light than the superficial ones.

254 However, incident light increased in summer and during periods characterized by low humidity 255 (Fig. 1c).

257 Detection of cave salamanders

258

Through the 180 cave surveys, we obtained 1087 detections of cave salamanders (289

260 adult males, 393 adult females, 49 not sexed adults and 356 juveniles). The average sampling

261 effort was of $7.5 \mathrm{~min} / \mathrm{sector}$. Salamanders were detected throughout the year with $13 \%$ of

262 detections in winter, $39 \%$ in spring, $30 \%$ in summer and $18 \%$ in autumn months. The model

263 assuming constant detection probability across sectors showed a lower AIC value (AIC: 53.3 )

264 than the model assuming that detection probability is related to distance from the entrance (AIC:

265 53.9). Detection probability of salamanders within sectors was high (detection probability \pm SE:

$266 \quad 0.75 \pm 0.12)$.

267

268 Analysis of occurrence of $\boldsymbol{H}$. italicus through the year

Presence of $H$. italicus was strongly related to month, and was generally associated with

271 sectors characterized by high humidity, low light and abundant M. menardi spiders (Table 3a, 
272 4a). Furthermore, significant interactions between month and temperature and between month

273 and humidity indicated different microhabitat selection patterns among months (Table 4a).

274 Specifically, in winter periods salamanders were associated with warmest sectors, while in

275 summer periods they were associated with coldest and most humid sectors (Fig. 2a, b).

276 The microhabitat selection pattern was similar if adults only were considered. Adults

277 were more abundant in sectors with low light and abundant M. menardi (Table 3b, 4b).

278 Furthermore, differences among months were strong, and the interactions between month and

279 both humidity and temperature were significant. Adults were associated with relatively cold

280 sectors during summer, while in winter they were associated with warmer sectors (Fig. 2c). In

281 summer, adults were associated with the most humid sectors; however, they showed a clear

282 preference for the most humid sectors also in February (Fig. 2d).

283 Juveniles were more frequent in sectors with high humidity and abundant M. menardi

284 spiders; furthermore the effect of month, and the interactions humidity-month and temperature-

285 month were significant (Table 3c, 4c). Juveniles were associated with the coldest sectors during

286 winter and with warmer sectors during spring (Fig. 2e). From late winter until spring, juveniles

287 were associated with sectors characterized by lower humidity, while during summer this

288 apparent preference shifted in favor of most humid sectors (Fig. 2f).

Analysis between contrasting seasons

As detection probability was imperfect, we repeated the analysis by focusing on the comparison between two contrasting seasons (winter/summer), in which migration of

294 salamanders is probably limited. During these two intervals we observed 112 salamanders in 
295 winter and 257 salamanders in summer. The results of this analysis were generally consistent

296 with the analysis of the full dataset. If all individuals were pooled, salamanders were associated

297 with the darkest sectors. Season strongly affected the presence of salamanders; furthermore, we

298 detected a significant interaction between temperature and season; the interaction between

299 humidity and season was marginally not significant (Table S1a). During these two seasons,

300 salamanders were generally associated with sectors in which microclimate was different from

301 outdoor climate conditions: in fact, they were associated with the most humid and cold sectors

302 during summer, while in winter they preferred relatively warm sectors (Fig. S1a, b). Results were

303 nearly identical in the analysis of adults-only (Table S1b; Fig. S1c, d). In the analysis of

304 juveniles, only the interaction between season and temperature remained significant (Table S1c,

305 Fig. S1e, f). However, it should be remarked that sample size was relatively small in this latter

306 analysis (112 juveniles observed), and this may have limited statistical power, compared to the

307 previous analyses.

308

309 Stability of habitat selection pattern

310

311 Most of equivalency tests were not significant, suggesting that habitat selection pattern

312 was consistent through months (Table 5). However, in the analyses of humidity considering all

313 individuals and juveniles only, niche equivalency was significantly lower than expected by

314 chance between February and June, and between February and July. Salamanders were more

315 tolerant for low-humidity habitats than during summer (Fig. 3). Conversely, if adults only were

316 analyzed, none of similarity tests were rejected (Table 5).

317

318 Discussion 
320 Caves are often described as stable environments (Romero 2012), but their features and the

321 distribution of their inhabitants shows strong fluctuations through the year, particularly in the

322 superficial sectors. No doubt, the strong seasonal variation of salamander distribution was mostly

323 dictated by the fluctuations of microhabitats. Nevertheless habitat preferences and requirements

324 may change across seasons, as in the case of juveniles that select microhabitats with slightly

325 different conditions in different times (Fig. 2e, f).

326 Cave depth represented the major gradient along with microhabitat features varied: as

327 expected, humidity always increased and light decreased in the deepest sectors. The relationship

328 between temperature and depth was more complex. During winter a positive relationship

329 between temperature and depth was observed, while the relationship became negative during the

330 warm months (Fig. 1a). Furthermore, all cave abiotic features (temperature, humidity and light)

331 followed the variation of external conditions, which indeed were the major cause of fluctuations

332 of internal microhabitats. While this influence was strongest in the first meters of the caves, it

333 remained clearly detectable at depths $>20 \mathrm{~m}$ (Fig. 1), and therefore influenced the conditions

334 experienced by salamanders.

335 During our surveys, detection probability of Hydromantes italicus was high, allowing us

336 to obtain many observations, which are a necessary prerequisite for any habitat association study.

337 The observation of $H$. italicus was strongly related to time of survey. As observed in other

338 studies (Ficetola, Pennati \& Manenti 2012; Lunghi, Manenti \& Ficetola 2014), salamanders were

339 strongly associated with sectors characterized by specific microhabitat features, such as high

340 humidity, low light and abundant spiders. Individuals showed differences in their response to

341 abiotic features, which resulted in a different distribution of salamanders inside caves (Ficetola,

342 Pennati \& Manenti 2013). Adults were associated with the wettest microclimates, while juveniles 
343 were present in apparently more stressful sectors as they were also present in sectors with lower

344 humidity and less suitable temperatures. Such presence of juveniles also in suboptimal

345 microhabitats has been observed also in other species of cave salamanders (Ficetola, Pennati \&

346 Manenti 2013), and may allow juveniles to exploit more superficial environments, where they

347 can find more food.

348 Beside some differences in habitat selection between adults and juveniles, a strong

349 interaction between temperature, humidity and time of survey was consistently observed in most

350 analyses (Table 2, 4, Fig. 2). For instance, salamanders tended to be associated to the coldest and

351 wettest sectors of caves, but this pattern was not evident during late winter/spring (Fig. 2a, b).

352 Such heterogeneity in habitat selection may occur both because individuals select different

353 conditions during different times or life stage (selection change hypothesis) or because of the

354 strong variability of available microhabitat conditions (environmental change hypothesis). In

355 principle, it might be also possible that in certain periods juveniles are forced to move toward

356 suboptimal areas because of competition with adults. However, this explanation is unlikely:

357 previous studies explicitly testing this hypotheses have found evidence that juveniles are not

358 displaced by adults (Ficetola, Pennati \& Manenti 2013), while behavioral analyses suggested

359 lack of competition for territories (Berti \& Corti 2010).

360 Our data mostly support the environmental change hypothesis. First, the temperature

361 gradient showed a clear inversion through the seasons (Fig. 1a). If salamanders always select the

362 same optimal temperature (about $10-15^{\circ} \mathrm{C}$; Fig. S2), they can only find such conditions in the

363 deepest sectors of caves, in which temperature are relatively warm during winter, and coolest

364 during summer. Actually, most of equivalency tests were not significantly different from random

365 expectations, indicating that the species consistently selected the same microhabitat. In other 
366 words, apparent changes in species-habitat relationships (e.g. positive relationship with

367 temperature in winter and negative relationship in summer) occurred because the habitat

368 occupied by salamander remained the same, but environmental gradients changed through the

369 time. As a consequence, the relationships between microclimatic conditions and salamanders

370 were not constant with time: in summer individuals tended to select the coldest, most humid

371 sectors of caves, while the relationship was different during winter months (Fig. 2, Table 5). In

372 practice, selection of the same habitat resulted in regression coefficients that were remarkably

373 different among seasons (Fig. 2). The difficulty of extrapolating regression results and linear

374 relationships beyond the limits of environmental gradients tested is a major issue in ecological

375 modelling (Randin et al. 2006; Zurell, Elith \& Schroder 2012). In principle, only sampling the

376 whole spectrum of potential habitat conditions may allow a full reconstruction of habitat

377 preferences, but this is not feasible in the real world, because the available environmental

378 gradients generally cover a limited range of conditions (Soberon \& Nakamura 2009; Elith,

379 Kearney \& Phillips 2010).

380 Most of variation in species-habitat relationships was likely caused by the seasonal

381 variation of temperature and humidity. Nevertheless, particularly in the analysis of humidity with

382 juveniles, tests of niche equivalency between late winter and summer months were consistently

383 rejected (Table 5). Cave salamanders are able to exploit the whole cave; therefore, if salamanders

384 just require optimal abiotic conditions they can remain in farthest sectors where suitable

385 microclimate is more stable. Conversely, in this study, salamanders during summer were

386 associated to more humid sectors than in winter. This suggests a higher tolerance for dry sectors

387 during winter, and supports the selection change hypothesis. Multiple, non-exclusive

388 explanations are possible for such selection change. First, newborns Hydromantes normally 
389 hatch at the end of summer (Lunghi et al. 2014). Therefore, in the following winter, acquiring

390 energy is a major priority for juveniles. The most superficial cave sectors are the ones with driest

391 microclimate (Table 2), but show the highest abundance of prey. Actually, in our study caves,

392 the potential prey richness [calculated as the summed $\mathrm{N}$ of species of Araneae (excluding $M$.

393 menardi) and Diptera, as these taxa are the major food items for cave salamanders (Vignoli,

394 Caldera \& Bologna 2006; Crovetto, Romano \& Salvidio 2012)] quickly decreases with depth

395 (generalized linear model with Poisson error, taking into account month of survey: $B \pm \mathrm{SE}=-$

$\left.3960.024 \pm 0.006, \chi^{2}{ }_{1}=201.3, P<0.0001\right)$. This indicates that juveniles may trade-off microclimatic

397 optima for food availability (Vlachos et al. 2014). Actually, the end of winter may be a

398 particularly important period, as in this period many invertebrates end their winter latency (Bale

399 \& Hayward 2010). Efficient exploitation of seasonal peaks of food resources may be a key of

400 fast development during the first years. Furthermore, the negative consequences of low humidity

401 may be stronger in summer. Low environmental temperature reduces metabolism in ectotherms,

402 which limits oxygen needs. As lungless salamanders exchange gasses mainly through their skin,

403 and the efficiency of this skin function increases with high level of moisture (Spotila 1972),

404 during the cold season the individuals could be more tolerant to low humidity because of their

405 lower respiration needs.

406 The peculiar physiology of plethodontids forces these salamanders to live within very

407 narrow typologies of habitat. However, under certain circumstances, individuals may select

408 conditions that are closer to their physiological limits (Kearney et al. 2013). This is likely the

409 case for juveniles. Underground environments suffer constant food scarcity (Romero 2009), but

410 juveniles require consistent food supply in order to grow and reach maturity. Scarce access to

411 food resources during juvenile stages poses major constraints on development, and may have 
412 prolonged consequences and even impact lifetime fitness (Wong \& Kölliker 2014). Therefore, in

413 certain months, young salamanders exploit superficial sectors with more stressful abiotic

414 conditions, but they receive enough food input from the outdoor environment to offset the risk.

415 In principle, the "optimal" habitat of a species should match species requirements for

416 multiple parameters, ranging from metabolism to water balance and food availability. However,

417 such "ideal" conditions are rarely available in the real world, and species have to deal with

418 environmental variability, which causes frequent changes of habitat conditions and resources

419 availability (Seebacher \& Alford 1999; Araújo et al. 2010; Fredericksen 2014). Our study

420 explores the complexity of habitat use patterns under variable conditions, and highlights

421 difficulties in determining habitat selection processes. When necessary resources are inversely

422 correlated along environmental gradients, habitat choice will be the results of a trade-off between

423 the multiple requirements of a species. We showed that such trade-off may be not constant with

424 time or life stage, as both species priorities and habitat features may change across time.

425 Individuals often require different resources depending on their life stage, and thus must shift

426 their habitat selection to exploit different environments to satisfy their needs (Cox \& Cresswell

427 2014; Dittmar et al. 2014; Webb et al. 2014). Habitat selection studies are often based on data

428 collected over temporal snapshots. However, seasonality is a pervasive feature of natural

429 environments, highlighting the importance to always take into account the potential seasonal

430 variation and considering the interactions between the requirement of individuals and the

431 variability of habitats.

432

433 Acknowledgements

434 We thank two reviewers for constructive comments on a previous version of this manuscript. 
435 GFF belongs to the Laboratoire d'Ecologie Alpine, which is part of Labex OSUG@2020.

436

437 Supplemental Information

438 Supplementary data associated with this article can be found, in the online version. 


\section{References}

442

443

444

445

446

447

448

449

450

451

452

453

454

455

456

457

458

459

460

461

462

463

464

465

466

467

468

469

470

471

472

473

474

475

476

477

478

479

480

481

482

483
Araújo CS, Candido DM, Araújo HFP, Dias SC, and Vasconcellos A. 2010. Seasonal variations in scorpion activities (Arachnida: Scorpiones) in an area of Caatinga vegetation in northeastern Brazil. Zoologia 27:372-376.

Bale JS, and Hayward SAL. 2010. Insect overwintering in a changing climate. The Journal of Experimental Biology 213:980-994.

Banks-Leite C, Pardini R, Boscolo D, Righetto Cassano C, Püttker T, Santos Barros C, and Barlow J. 2014. Assessing the utility of statistical adjustments for imperfect detection in tropical conservation science. Journal of Applied Ecology 51:849-859.

Berti R, and Corti C. 2010. Relazione del progetto: Difesa del territorio in Speleomantes italicus. TALP Rivista della FST 40:44-53.

Bogaerts S, Sparreboom M, Pasmans F, Almasri A, Beukema W, Shehab A, and Amr ZS. 2013. Distribution, ecology and conservation of Ommatotriton vittatus and Salamandra infraimmaculata in Syria. Salamandra 49:87-96.

Brambilla M, and Saporetti F. 2014. Modelling distribution of habitats required for different uses by the same species: Implications for conservation at the regional scale. Biological Conservation 174:39-46.

Briggler JT, and Prather JW. 2006. Seasonal use and selection of caves by plethodontid salamanders in a Karst area of Arkansas. American Midland Naturalist 155:136-148.

Broennimann O, Fitzpatrick MC, Pearman PB, Petitpierre B, Pellissier L, Yoccoz NG, Thuiller W, Fortin M-J, Randin C, Zimmermann NE, Graham CH, and Guisan A. 2012. Measuring ecological niche overlap from occurrence and spatial environmental data. Global Ecology and Biogeography 21:481-497.

Camp CD, and Jensen JB. 2007. Use of twilight zones of caves by plethodontid salamanders. Copeia:594-604.

Camp CD, Wooten JA, Jensen JB, and Bartek DF. 2014. Role of temperature in determining relative abundance in cave twilight zones by two species of lungless salamander (family Plethodontidae). Canadian Journal of Zoology 92:119-127.

Cox DTC, and Cresswell W. 2014. Mass gained during breeding positively correlates with adult survival because both reflect life history adaptation to seasonal food availability. Oecologia 174:1197-1204.

Crovetto F, Romano A, and Salvidio S. 2012. Comparison of two non-lethal methods for dietary studies in terrestrial salamanders. Wildlife Research 39:266-270.

Crump ML, and Scott J, N. J. 1994. Visual Encounter Surveys. In: Heyer WR, Donnelly MA, McDiarmid RW, Hayek LC, and Foster MS, eds. Measuring and monitoring biological diversity: standard methods for Amphibians. Washington: Smithsonian Institution Press, 84-92.

Dail D, and Madsen L. 2011. Models for estimating abundance from repeated counts of an open metapopulation. Biometrics 67:577-587.

Dittmar EM, Cimprich DA, Sperry JH, and Weatherhead PJ. 2014. Habitat selection by juvenile black-capped vireos following independence from parental care. Journal of Wildlife Management 78:1005-1011.

Domíguez-Vega H, Monroy-Vilchis O, Balderas-Valdivia CJ, Gienger CM, and Ariano-Sánchez 
484

485

486

487

488

489

490

491

492

493

494

495

496

497

498

499

500

501

502

503

504

505

506

507

508

509

510

511

512

513

514

515

516

517

518

519

520

521

522

523

524

525

526

527

528

529
D. 2012. Predicting the potential distribution of the beaded lizard and identification of priority areas for conservation. Journal for Nature Conservation 20:247-253.

Elith J, Kearney M, and Phillips S. 2010. The art of modelling range-shifting species. Methods in Ecology and Evolution 1:330-342.

Ficetola GF, Pennati R, and Manenti R. 2012. Do cave salamanders occur randomly in cavities? An analysis with Hydromantes strinatii. Amphibia-Reptilia 33:251-259.

Ficetola GF, Pennati R, and Manenti R. 2013. Spatial segregation among age classes in cave salamanders: habitat selection or social interactions? Population Ecology 55:217-226.

Fiske IJ, and Chandler RB. 2011. Unmarked: an R package for fitting hierarchical models of wildlife occurrence and abundance. Journal of Statistical Software 43:1-23.

Fox J. 2002. An R and S-PLUS companion to applied regression. Thousand Oaks, CA: SAGE Publications.

Fredericksen TS. 2014. Thermal regulation and habitat use of the eastern box turtle in southwestern Virginia. Northeastern Naturalist 21:554-564.

Godsoe W. 2010. I can't define the niche but I know it when I see it: a formal link between statistical theory and the ecological niche. Oikos 119:53-60.

Guisan A, and Thuiller W. 2005. Predicting species distribution: offering more than simple habitat models. Ecology Letters 8:993-1009.

Jung RE, Droege S, Sauer JR, and Landy RB. 2000. Evaluation of terrestrial and streamside salamander monitoring techniques at Shenandoh National Park. Environmental Monitoring and Assessment 63:65-79.

Kearney M, and Porter W. 2009. Mechanistic niche modelling: combining physiological and spatial data to predict species ranges. Ecology Letters 12:334-350.

Kearney MR, Simpson SJ, Raubenheimer D, and Kooijman SALM. 2013. Balancing heat, water and nutrients under environmental change: a thermodynamic niche framework.

Functional Ecology 27:950-965.

Lanza B, Pastorelli C, Laghi P, and Cimmaruta R. 2006. A review of systematics, taxonomy, genetics, biogeography and natural history of the genus Speleomantes Dubois, 1984 (Amphibia Caudata Plethodontidae). Atti del Museo Civico di Storia Naturale di Trieste 52.

Lunghi E, Manenti R, and Ficetola GF. 2014. Do cave features affect underground habitat exploitation by non-troglobite species? Acta Oecologica 55:29-35.

Lunghi E, Manenti R, Manca S, Mulargia M, Pennati R, and Ficetola GF. 2014. Nesting of cave salamanders (Hydromantes flavus and H. italicus) in natural environments. Salamandra:105-109.

MacKenzie DI, and Kendall WL. 2002. How should detection probability be incorporated into estimates of relative abundance? (vol 83, pg 2387, 2002). Ecology 83:3532-3532.

MacKenzie DI, Nichols JD, Royle JA, Pollock KH, Bailey LL, and Hines JE. 2006. Occupancy Estimation and Modeling. Inferring Patterns and Dynamics of Species Occurrence: Academic Press.

Nogués-Bravo D. 2009. Predicting the past distribution of species climatic niches. Global Ecology and Biogeography 18:521-531.

Peterson AT, Soberón J, Pearson RG, Anderson RP, Martínez-Meyer E, Nakamura M, and Araújo MB. 2011. Ecological niches and geographic distributions. Princeton, NJ: Princeton University Press.

Randin CF, Dirnbock T, Dullinger S, Zimmermann NE, Zappa M, and Guisan A. 2006. Are 
niche-based species distribution models transferable in space? Journal of Biogeography 33:1689-1703.

Rice WR. 1989. Analyzing tables of statistical tests. Evolution 43:223-225.

Richards SA, Whittingham MJ, and Stephens PA. 2011. Model selection and model averaging in behavioural ecology: the utility of the IT-AIC framework. Behavioral Ecology and Sociobiology 65:77-89.

Romero A. 2009. Cave biology. New York: Cambridge University Press.

Romero A. 2012. Caves as biological space. Polymath: An Interdisciplinary Arts and Sciences Journal 2:15.

Salvidio S, Lattes A, Tavano M, Melodia F, and Pastorino MV. 1994. Ecology of a Speleomantes ambrosii population inhabiting an artificial tunnel. Amphibia-Reptilia 15:35-45.

Saupe EE, Hendricks JR, Portell RW, Dowsett HJ, Haywood A, Hunter SJ, and Lieberman BS. 2014. Macroevolutionary consequences of profound climate change on niche evolution in marine molluscs over the past three million years. Proceeding of The Royal Society of London Series B 281:20141995.

Seebacher F, and Alford RA. 1999. Movement and microhabitat use of a terrestrial amphibian (Bufo marinus) on a tropical island: seasonal variation and environmental correlates. Journal of Herpetology 33:208-214.

Sewell D, Beebee TJ, and Griffiths RA. 2010. Optimising biodiversity assessments by volunteers: The application of occupancy modelling to large-scale amphibian surveys. Biological Conservation 143:2102-2110.

Soberon J, and Nakamura M. 2009. Niches and distributional areas: Concepts, methods, and assumptions. Proceedings of the National Academy of Sciences of the United States of America PNAS 106:19644-19650.

Spotila JR. 1972. Role of temperature and water in the ecology of lungless salamanders. Ecological Monographs 42:95-125.

Stein A, Gerstner K, and Kreft H. 2014. Environmental heterogeneity as a universal driver of species richness across taxa, biomes and spatial scales. Ecology Letters 17:866-880.

Stephens PA, Buskirk SW, Hayward GD, and Del Rio CM. 2007. A call for statistical pluralism answered. Journal of Applied Ecology 44:461-463.

Stigall AL. 2012. Using ecological niche modelling to evaluate niche stability in deep time. Journal of Biogeography 39:772-781.

Vignoli L, Caldera F, and Bologna MA. 2006. Trophic niche of cave populations of Speleomantes italicus. Journal of Natural History 40:1841-1850.

Vignoli L, Caldera F, and Bologna MA. 2008. Spatial niche of the Italian cave salamander, Speleomantes italicus (Dunn, 1923) (Plethodontidae, Amphibia), in a subterranean system of Central Italy. Italian Journal of Zoology 75:59-65.

Vlachos CG, Bakaloudis DE, Kitikidou K, Goutner V, Bontzorlos V, Papakosta MA, and Chatzinikos E. 2014. Home range and foraging habitat selection by breeding lesser kestrels (Falco naumanni) in Greece. Journal of Natural History 49:371-381.

Warren DL. 2012. In defense of 'niche modeling'. Trends in Ecology and Evolution 27:497-500.

Warren DL, Glor RE, and Turelli M. 2008. Environmental niche equivalency versus conservatism: quantitative approaches to niche evolution. Evolution 62:2868-2883.

Webb LE, Engel B, Berends H, van Reenena CG, Gerrits WJJ, de Boer IJM, and Bokkers EAM. 2014. What do calves choose to eat and how do preferences affect behaviour? Applied 
Animal Behaviour Science 161:7-19.

577 Wong JWY, and Kölliker M. 2014. Effects of food restriction across stages of juvenile and early

578

579 adult development on body weight, survival and adult life history. Journal of Evolutionary Biology 27:2420-2430.

580 Zurell D, Elith J, and Schroder B. 2012. Predicting to new environments: tools for visualizing model behaviour and impacts on mapped distributions. Diversity and Distributions

582 18:628-634.

583

584

585

586 
Table $\mathbf{1}_{\text {(on next page) }}$

Best AIC models explaining the variation in microhabitat features of caves.

Table 1: Best AIC models explaining the variation in microhabitat features of caves.

We considered as dependent variables inner abiotic features of caves: a) Temperature, $b$ ) Humidity and c) Illuminance. We used as independent variables: Month of survey, Time in which the survey began, Depth of sector, External Temperature, External Humidity and interaction between Month and Depth (Prof : M). For each continuous variable, the regression coefficient is reported if the variable is included into a given model. For both categorical variables and interaction, + indicates their presence into the model. For each independent variable, we report the first five best models. 


\begin{tabular}{|c|c|c|c|c|c|c|c|c|c|}
\hline \multicolumn{6}{|c|}{ Independent variables included into the model } & \multirow[t]{2}{*}{ df } & \multirow[t]{2}{*}{ AICc } & \multirow[t]{2}{*}{$\Delta$-AICc } & \multirow[t]{2}{*}{ weigh } \\
\hline Month & Time of survey & Depth & $\begin{array}{c}\text { External } \\
\text { Temperature }\end{array}$ & $\begin{array}{l}\text { External } \\
\text { Humidity }\end{array}$ & Prof : $\mathbf{M}$ & & & & \\
\hline \multicolumn{10}{|c|}{ a) Temperature } \\
\hline+ & & 0.07 & 0.22 & 0.02 & + & 29 & 5703 & 0 & 0.825 \\
\hline+ & 0.05 & 0.07 & 0.21 & 0.02 & + & 30 & 5706.3 & 3.34 & 0.155 \\
\hline+ & & 0.07 & 0.18 & & + & 28 & 5710.5 & 7.50 & 0.019 \\
\hline+ & 0.01 & 0.07 & 0.18 & & + & 29 & 5717.6 & 14.67 & 0.001 \\
\hline+ & 0.12 & 0.07 & & & + & 28 & 5811.7 & 108.78 & 0 \\
\hline \multicolumn{10}{|c|}{ b) Humidity } \\
\hline+ & 0.34 & 0.27 & & 0.15 & + & 29 & 8314.1 & 0 & 0.517 \\
\hline+ & 0.31 & 0.27 & 0.11 & 0.16 & + & 30 & 8314.2 & 0.15 & 0.480 \\
\hline+ & 0.26 & 0.24 & 0.15 & 0.17 & & 19 & 8325.2 & 11.09 & 0.002 \\
\hline+ & & 0.27 & 0.16 & 0.15 & + & 29 & 8329.8 & 15.75 & 0 \\
\hline+ & 0.31 & 0.24 & & 0.16 & & 18 & 8329.8 & 15.75 & 0 \\
\hline \multicolumn{10}{|c|}{ c) Illuminance } \\
\hline & & -0.04 & & -0.01 & & 6 & 3232.3 & 0 & 0.967 \\
\hline & & -0.04 & 0.01 & -0.01 & & 7 & 3239.7 & 7.41 & 0.024 \\
\hline & -0.01 & -0.04 & & -0.01 & & & 3241.7 & 9.40 & 0.009 \\
\hline & -0.01 & -0.04 & 0.01 & -0.01 & & & 3248.7 & 16.39 & 0 \\
\hline & & -0.04 & 0.01 & & & & 3256 & 23.72 & 0 \\
\hline
\end{tabular}

1 
Figure $\mathbf{1}_{\text {(on next page) }}$

Annual variation of external environment and cave microhabitat.

Figure 1: Annual variation of external environment and cave microhabitat. Internal variables are a) temperature, b) humidity and c) illuminance (lux). In each graph, colored plots represent sectors located at different distance from the entrance (from 3 to $21 \mathrm{~m}$ ). These sectors represent the area in which microclimate variability is higher; at $21 \mathrm{~m}$ illuminance was constantly 0 lux. Error bars are standard errors. For temperature and humidity, the trend of the respective external feature is also shown, represented by a continuous red line. 

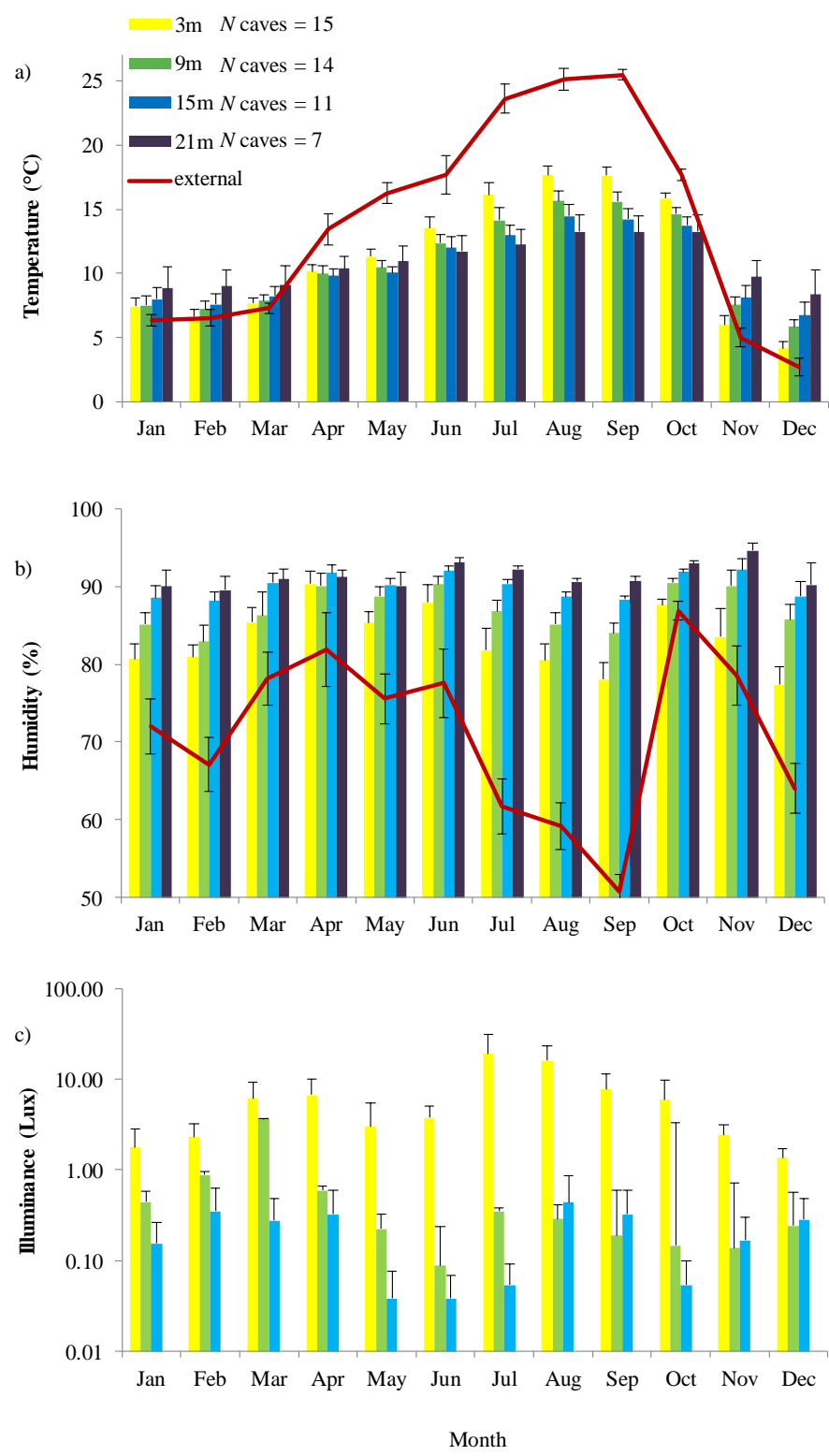
Table 2 (on next page)

Parameters related to microclimatic change of caves through the year: best-AICC models.

Table 2: Parameters related to microclimatic change of caves through the year: best-AICc models. The dependent variables were three major features of cave microclimate: a) internal temperature, b) internal humidity and c) illuminance. Independent variables were: Month of survey, Depth of sector, Temp. ext (external temperature), Hum. ext (external humidity), Time (hour of survey). 


\begin{tabular}{lrrr}
\hline Factor & $B$ & \multicolumn{1}{c}{$\chi^{2}{ }_{1}$} & \multicolumn{1}{c}{$P$} \\
\hline a) Temperature (internal) & & & \\
& & & \\
Month & 0.07 & 0.81 & 0.368 \\
Depth & 0.21 & 144.2 & $<\mathbf{0 . 0 0 1}$ \\
Temp. ext & 0.02 & 18.96 & $<\mathbf{0 . 0 0 1}$ \\
Hum. ext & & 680.71 & $<\mathbf{0 . 0 0 1}$ \\
Month $\times$ Depth & & & \\
& & & \\
b) Humidity (internal) & & & \\
& & 117.03 & $<\mathbf{0 . 0 0 1}$ \\
Month & 0.27 & 105.91 & $<\mathbf{0 . 0 0 1}$ \\
Depth & 0.16 & 205.3 & $<\mathbf{0 . 0 0 1}$ \\
Hum. ext & & 27.95 & $<\mathbf{0 . 0 0 1}$ \\
Time & & 94.92 & $<\mathbf{0 . 0 0 1}$ \\
Month $\times$ Depth & & & \\
& & & \\
c) Illuminance & & & \\
& -0.03 & 34.60 & $<\mathbf{0 . 0 0 1}$ \\
Depth & -0.01 & 49.66 & $<\mathbf{0 . 0 0 1}$ \\
Hum. ext & & & \\
\hline
\end{tabular}

1 


\section{Table 3(on next page)}

Five best AIC models relating salamander distribution to environmental features.

\section{Table 3: Five best AIC models relating salamander distribution to environmental}

features. We considered as dependent variable the presence of a) the species, b) presence of Adults and c) presence of Juveniles. We used as independent variables: internal humidity (Humid), Month of survey, illuminance (Lux), Meta spiders abundance and internal temperature (Temp). Furthermore, we also used as independent variables interaction between month and internal humidity (Hum : M), month and illuminance (Lux : M), month and Meta spiders (Meta : M) and month and internal temperature (Temp : M). For each continuous variable, the regression coefficient is reported if the variable is included into a given model. For categorical variables and interactions, + indicates that the variable or the interaction is included into the model. 
1

\begin{tabular}{|c|c|c|c|c|c|c|c|c|c|c|c|c|}
\hline \multicolumn{9}{|c|}{ Independent variables included into the model } & \multirow[t]{2}{*}{ df } & \multirow[t]{2}{*}{ AICc } & \multirow[t]{2}{*}{$\Delta$-AICc } & \multirow[t]{2}{*}{ weight } \\
\hline Humid & Month & Lux & Meta & Temp & $\begin{array}{c}\text { Hum : } \\
\quad M\end{array}$ & $\begin{array}{c}\text { Lux : } \\
\quad M\end{array}$ & $\begin{array}{c}\text { Meta: } \\
\text { M }\end{array}$ & $\begin{array}{c}\text { Temp } \\
: M\end{array}$ & & & & \\
\hline \multicolumn{13}{|c|}{ a) presence of the species } \\
\hline 1.12 & + & -0.34 & 0.44 & 0.27 & + & & & + & 40 & 1384.8 & $\mathbf{0}$ & 0.709 \\
\hline 1.64 & + & -0.36 & & 0.26 & + & + & & + & 39 & 1388.9 & 4.15 & 0.089 \\
\hline-2.47 & + & -20.74 & 0.45 & 0.25 & + & & & + & 51 & 1389.3 & 4.5 & 0.075 \\
\hline 1.41 & + & & 0.45 & 0.27 & + & & & + & 39 & 1390.2 & 5.45 & 0.046 \\
\hline 7.79 & + & -0.35 & 0.43 & & + & & & & 28 & 1392.1 & 7.35 & 0.018 \\
\hline
\end{tabular}

b) presence of Adults

\begin{tabular}{|c|c|c|c|c|c|c|c|c|c|c|c|c|}
\hline 1.27 & + & -0.43 & 0.39 & 0.16 & + & & & + & 40 & 1253.8 & $\mathbf{0}$ & 0.721 \\
\hline 1.7 & + & -0.44 & & 0.16 & + & & & + & 39 & 1256.2 & 2.44 & 0.213 \\
\hline 1.67 & + & & 0.42 & 0.16 & + & & & + & 39 & 1261 & 7.25 & 0.019 \\
\hline 6.83 & + & -0.42 & 0.4 & & + & & & & 28 & 1261.5 & 7.78 & 0.015 \\
\hline 1.46 & + & -0.44 & -0.15 & 0.18 & + & & + & + & 51 & 1262.7 & 8.92 & 0.008 \\
\hline \multicolumn{13}{|c|}{ c) presence of Juveniles } \\
\hline 1.46 & + & & 0.61 & 0.41 & + & & & + & 39 & 807.2 & $\mathbf{0}$ & 0.428 \\
\hline 1.23 & + & -0.26 & 0.58 & 0.4 & + & & & + & 40 & 807.3 & 0.1 & 0.407 \\
\hline 2.14 & + & -0.3 & & 0.39 & + & & & + & 39 & 810.5 & 3.22 & 0.085 \\
\hline 2.57 & + & & & 0.39 & + & & & + & 38 & 810.8 & 3.57 & 0.072 \\
\hline-2.85 & + & -20.8 & 0.59 & 0.35 & + & + & & + & 51 & 816 & 8.72 & 0.005 \\
\hline
\end{tabular}

2 
Table 4 (on next page)

Parameters related to presence/absence of salamanders.

Table 4: Parameters related to presence/absence of salamanders. The dependent variables were the presence of a) Species, b) Adults only and c) Juveniles only. See Table 1 for explanation of variable names. Only the best-AICc models are shown. 


\begin{tabular}{lrrr}
\hline \multicolumn{1}{c}{ Factor } & \multicolumn{1}{c}{$B$} & \multicolumn{1}{c}{$\chi^{2}{ }^{2}$} & \multicolumn{1}{c}{$P$} \\
\hline a) Species & & & \\
Month & & 140.2 & $<\mathbf{0 . 0 0 1}$ \\
Humidity & -2.65 & 4.3 & $\mathbf{0 . 0 3 9}$ \\
Lux & -20.79 & 7.6 & $\mathbf{0 . 0 0 6}$ \\
Meta abund. & 0.36 & 6.3 & $\mathbf{0 . 0 1 2}$ \\
Temperature & 0.25 & 1.4 & 0.238 \\
Hum $\times$ Month & & 30.6 & $\mathbf{0 . 0 0 1}$ \\
Temp $\times$ Month & & 31.2 & $\mathbf{0 . 0 0 1}$ \\
& & & \\
b) Adults & & & \\
& & & \\
Month & & 128.7 & $<\mathbf{0 . 0 0 1}$ \\
Humidity & -1.57 & 1.4 & 0.233 \\
Lux & -1.95 & 9.4 & $\mathbf{0 . 0 0 2}$ \\
Meta abund. & -2.31 & 4.6 & $\mathbf{0 . 0 3 3}$ \\
Temp & 1.74 & 0.3 & 0.567 \\
Hum $\times$ Month & & 37.3 & $<\mathbf{0 . 0 0 1}$ \\
Temp $\times$ Month & & 32.7 & $<\mathbf{0 . 0 0 1}$ \\
& & & \\
c) Juveniles & & & \\
Month & & & \\
Humidity & -3.60 & 5.4 & $\mathbf{0 . 0 2}$ \\
Meta abund. & 0.75 & 5.7 & $\mathbf{0 . 0 1 7}$ \\
Temp & 0.35 & 3.6 & 0.059 \\
Hum $\times$ Month & & 37 & $<\mathbf{0 . 0 0 1}$ \\
Temp $\times$ Month & & 39 & $<\mathbf{0 . 0 0 1}$ \\
\hline & & &
\end{tabular}

1 


\section{Figure 2 (on next page)}

Annual variation of the coefficients of regressions between presence/absence of cave salamanders, temperature and humidity.

Figure 2: Annual variation of the coefficients of regressions between presence/absence of cave salamanders, temperature and humidity. a-b): results of regression models analyzing all individuals encountered; c-d) results of models analyzing adults only e-f) results of models analyzing juveniles only. Results for December were not reported due to small sample size. 


\section{PeerJ Reviewing Manuscript}

\section{Temperature}

\section{Humidity}

Analysis of the presence of the species

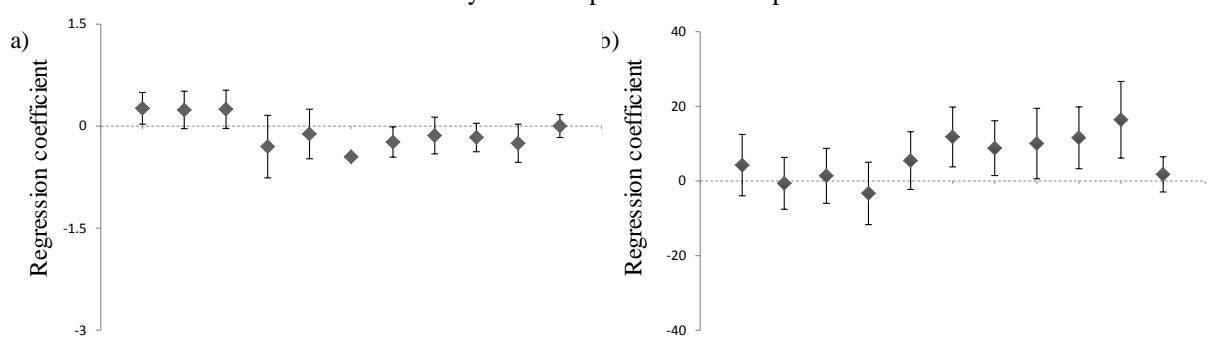

Analysis of the presence of adults

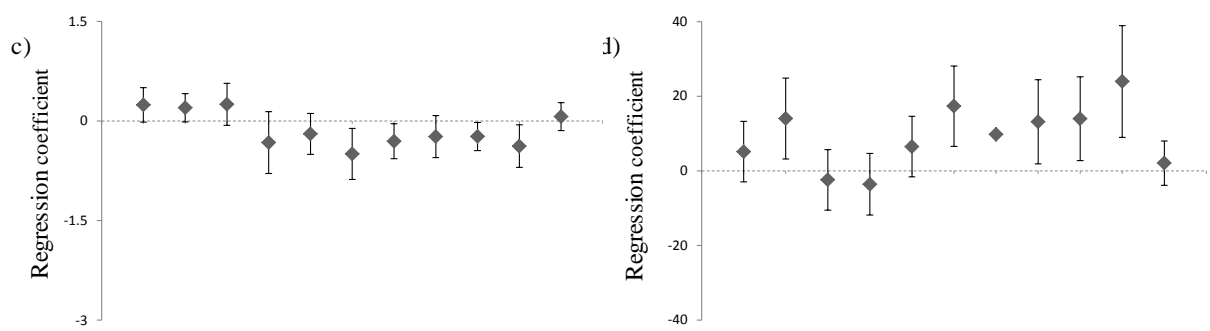

Analysis of the presence of juveniles

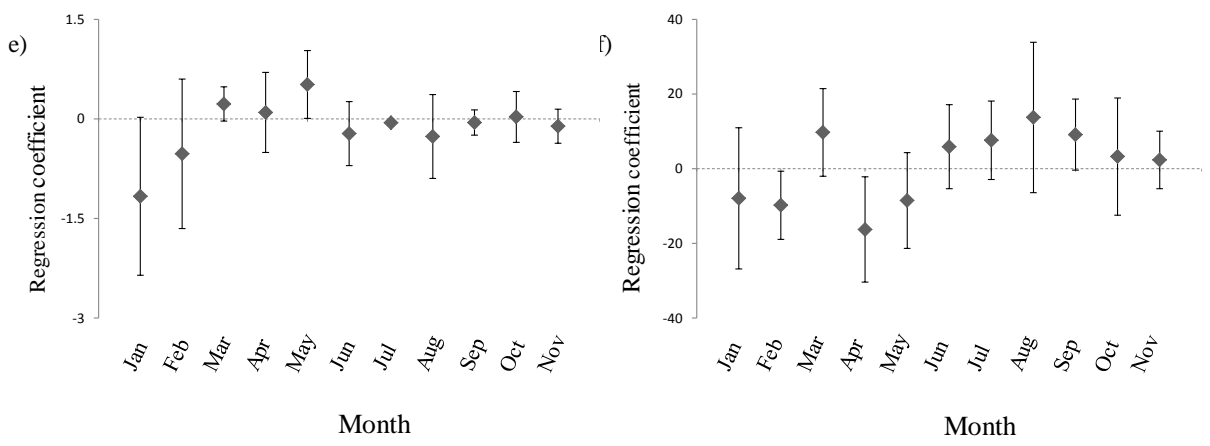


Table 5 (on next page)

Equivalency of species-habitat relationships (measured as Shoener's $D$ ) observed in different months.

Table 5. Equivalency of species-habitat relationships (measured as Shoener's $\boldsymbol{D}$ )

observed in different months. Pairs of months for which the species-habitat relationships were not equivalent (after Bonferroni's correction: $\alpha^{\prime}=0.0083$ ) are in bold. 


\begin{tabular}{|c|c|c|c|c|c|c|}
\hline & \multicolumn{3}{|c|}{ Temperature } & \multicolumn{3}{|c|}{ Humidity } \\
\hline \multicolumn{7}{|c|}{ a) All individuals } \\
\hline & Feb & Jun & Jul & Feb & Jun & Jul \\
\hline Jan & 0.917 & 0.684 & 0.771 & 0.520 & 0.695 & 0.762 \\
\hline Feb & & 0.616 & 0.639 & & 0.336 & 0.375 \\
\hline Jun & & & 0.832 & & & 0.770 \\
\hline \multicolumn{7}{|c|}{ b) Adults only } \\
\hline & Feb & Jun & Jul & Feb & Jun & Jul \\
\hline Jan & 0.844 & 0.644 & 0.703 & 0.650 & 0.595 & 0.612 \\
\hline Feb & & 0.704 & 0.795 & & 0.650 & 0.601 \\
\hline Jun & & & 0.790 & & & 0.650 \\
\hline \multicolumn{7}{|c|}{ c) Juveniles only } \\
\hline & Feb & Jun & Jul & Feb & Jun & Jul \\
\hline Jan & 0.807 & 0.688 & 0.601 & 0.234 & 0.706 & 0.693 \\
\hline $\mathrm{Feb}$ & & 0.528 & 0.428 & & 0.077 & 0.069 \\
\hline Jun & & & 0.700 & & & 0.950 \\
\hline
\end{tabular}




\section{Figure $\mathbf{3}$ (on next page)}

Violin plots representing humidity in cave sectors available (white) and occupied by cave salamanders (grey), during three months.

Figure 3: Violin plots representing humidity in cave sectors available (white) and occupied by cave salamanders (grey), during three months. The area of violin plots represents the distribution of cave sectors according to microclimate feature. Width of plots is proportional to the number of sectors showing such microclimate condition. The black points represent the medians, the grey boxes represent the second and third quartiles. The violin plots for temperature are available in Fig. S2. 
PeerJ Reviewing Manuscript

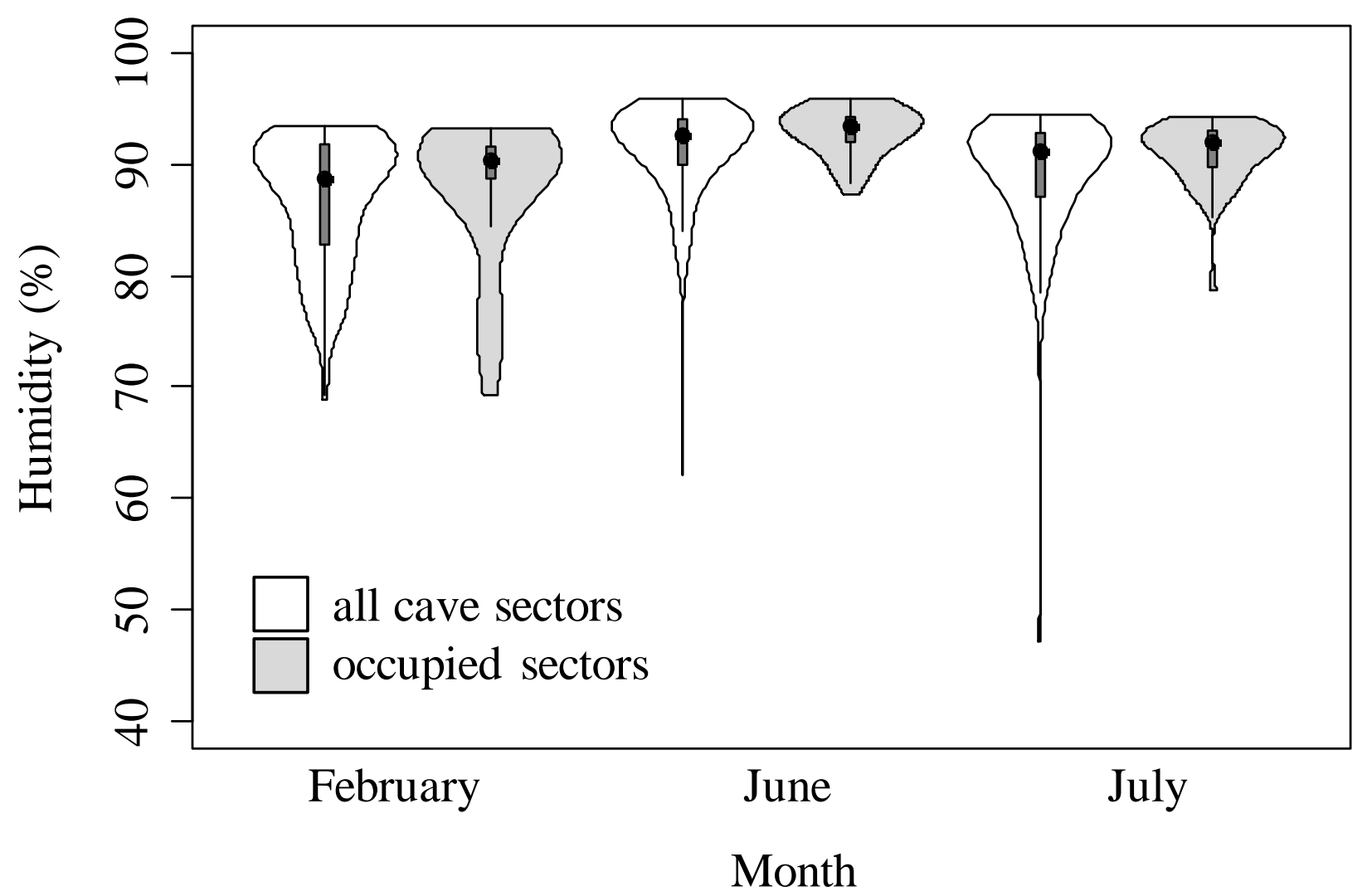

